\title{
Pragmatic Strengthening in Plural Predications and Donkey Sentences
}

\author{
Manfred Krifka \\ University of Texas at Austin
}

\section{Universal and Existential Interpretations of Donkey Sentences}

The classical analysis of donkey sentences like (1.a,b) in Kamp (1981) and Heim (1982) assigns them truth conditions as given in (2.a). That is, they are treated as quantifications over farmer-donkey pairs. Partee (1984) and Kadmon (1987) have pointed out that the proper reading of (1.b), and a pref erred reading of (1.a), is rather a quantification over farmers, as illustrated in (2.b).

(1) a. If a farmer owns a donkey, he usually beats it.

b. Most farmers who own a donkey beat it.

$$
\begin{array}{cc}
\text { a. } & \operatorname{MOST}(\{\langle\mathrm{x}, \mathrm{y}\rangle \mid \operatorname{FARMER}(\mathrm{x}) \wedge \operatorname{DONKEY}(\mathrm{y}) \wedge \operatorname{OWN}(\mathrm{x}, \mathrm{y})\}, \\
& \{\langle\mathrm{x}, \mathrm{y}\rangle \mid \operatorname{BEAT}(\mathrm{x}, \mathrm{y})\}) \\
\text { b. } & \operatorname{MOsT}(\{\mathrm{x} \mid \exists \mathrm{y}[\operatorname{FARMER}(\mathrm{x}) \wedge \operatorname{DONKEY}(\mathrm{y}) \wedge \operatorname{OWN}(\mathrm{x}, \mathrm{y})]\}, \\
& \{\mathrm{x} \mid \mathrm{x} \operatorname{BEATS}(\operatorname{DONKEY} \operatorname{OF}(\mathrm{x}))\}) \\
\text { c. } & \operatorname{MOST}(\mathrm{A}, \mathrm{B}) \Leftrightarrow \operatorname{card}(\mathrm{A} \cap \mathrm{B})>\operatorname{card}(\mathrm{A}-\mathrm{B})
\end{array}
$$

(2.a) is called the symmetric interpretation, and (2.b) the (subject-) asymmetric interpretation by Kadmon (1987). In (2.b), the donkey variable y is called dependent. With asymmetric interpretations the question arises how the dependent variable is interpreted within the second argument, the nuclear scope. This issue is taken up in Rooth (1987). He distinguishes two cases, a "weak" or existential interpretation as in (3.a), and a "strong" or universal interpretation as in (3.b). ${ }^{1}$

$$
\begin{aligned}
& \text { a. } \operatorname{MOST}(\{x \mid \exists y[\operatorname{FARMER}(x) \wedge \operatorname{DONKEy}(y) \wedge \operatorname{OWN}(x, y)]\} \text {, } \\
& \{\mathrm{x} \mid \exists \mathbf{y}[\operatorname{FARMER}(\mathrm{x}) \wedge \operatorname{DONKEy}(\mathrm{y}) \wedge \mathrm{OWN}(\mathrm{x}, \mathrm{y}) \wedge \operatorname{BEAT}(\mathrm{x}, \mathrm{y})]\}) \\
& \text { b. } \operatorname{MOST}(\{\mathrm{x} \mid \exists \mathrm{y}[\operatorname{FARMER}(\mathrm{x}) \wedge \operatorname{DONKEy}(\mathrm{y}) \wedge \operatorname{OWN}(\mathrm{x}, \mathrm{y})]\} \text {, } \\
& \{\mathrm{x} \mid \forall \mathbf{y}[\operatorname{FARMER}(\mathrm{x}) \wedge \operatorname{DONKEY}(\mathrm{y}) \wedge \operatorname{OWN}(\mathrm{x}, \mathrm{y})] \rightarrow \operatorname{BEAT}(\mathrm{x}, \mathrm{y})]\})
\end{aligned}
$$

(3.a) says that most farmers that own a donkey beat at least one of their donkeys. (3.b) says that most of those farmers beat each of their donkeys. The question is: What determines the choice of reading in asymmetric quantifications?

\section{Upward- and Downward-Entailing Contexts}

Rooth (1987) observes that there is a correlation between existential and universal interpretation of the dependent variable and the quantifier of the donkey sentence: 
Quantifiers like every and most favor an existential interpretation, quantifiers like no favor a universal interpretation:
a. Every farmer that owns a donkey beats it. $\operatorname{EVERY}(\{\mathrm{x} \mid \exists \mathrm{y}[\operatorname{FARMER}(\mathrm{x}) \wedge \operatorname{DONKEY}(\mathrm{y}) \wedge \mathrm{OWN}(\mathrm{x}, \mathrm{y})]\}$, $\{\mathrm{x} \mid \forall \mathrm{y}[\operatorname{FARMER}(\mathrm{x}) \wedge \operatorname{DONKEY}(\mathrm{y}) \wedge \operatorname{OWN}(\mathrm{x}, \mathrm{y})] \rightarrow \operatorname{BEAT}(\mathrm{x}, \mathrm{y})]\})$
b. No farmer that owns a donkey beats it. $\operatorname{NO}(\{x \mid \exists y[\operatorname{FARMER}(x) \wedge \operatorname{DONKEY}(y) \wedge \operatorname{OWN}(x, y)]\}$, $\{\mathrm{x} \mid \exists \mathrm{y}[\operatorname{FARMER}(\mathrm{x}) \wedge \operatorname{DONKEY}(\mathrm{y}) \wedge \operatorname{OWN}(\mathrm{x}, \mathrm{y}) \wedge \operatorname{BEAT}(\mathrm{x}, \mathrm{y})]\})$
c. $\operatorname{EVERY}(A, B) \Leftrightarrow A \subseteq B, N O(A, B) \Leftrightarrow A \cap B=\varnothing$.

In typical circumstances ${ }^{2}$, a sentence like (4.a) would be considered false if there is some farmer that does not beat all of his donkeys, and a sentence like (4.b) would be considered false if there is some farmer that beats one of his donkeys, even if he does not beat his other donkeys.

One crucial property that distinguishes quantifiers like every and most on the one hand and no on the other is that every and most are upward entailing in their nuclear scope, whereas no is downward entailing. Hence a promising hypothesis is that quantifiers that are upward entailing prefer the existential interpretation of the dependent variable, whereas downward entailing quantifiers prefer the universal interpretation. Kanazawa (1994) calls this Rooth's Generalization. Other examples that confirm this hypothesis can be found easily. The following downward-entailing quantifiers clearly prefer the existential interpretation of the dependent variable. For example, (5.a) says that few farmers who own a donkey beat any of their donkeys.

a. Few farmers who own a donkey beat it.

b. At most three farmers who own a donkey beat it.

Kanazawa points out a problem with Rooth's Generalization: The quantifier not every, though downward entailing in its standard analysis (6.b), does not behave as expected. Sentence (6.a) expresses that there is at least one farmer that does not beat any of his donkeys, that is, the dependent variable is interpreted universally:
a. Not every farmer who owns a donkey beats it.
NOTEVERY $(\{x \mid \exists y[\operatorname{FARMER}(x) \wedge \operatorname{DONKEY}(y) \wedge \operatorname{OWN}(\mathrm{x}, \mathrm{y})]\}$, $\{\mathrm{x} \mid \forall \mathrm{y}[\operatorname{FARMER}(\mathrm{x}) \wedge \operatorname{DONKEY}(\mathrm{y}) \wedge \operatorname{OWN}(\mathrm{x}, \mathrm{y}) \rightarrow \operatorname{BEAT}(\mathrm{x}, \mathrm{y})]\})$
b. $\operatorname{NOTEVERY}(\mathrm{A}, \mathrm{B}) \Leftrightarrow \neg \mathrm{A} \subseteq \mathrm{B}$

Not every, analyzed as a quantificational determiner, is a proportional determiner that is downward entailing in its nuclear scope; a sentence like Not every $A B$ expresses that less than 100 percent of the A have the property B. Interestingly, other quantifiers of this type abide by Rooth's Generalization. For example, less than 90 percent of the clearly prefers the existential interpretation of the depend- 
ent variable. Sentence (7.a) says that less than 90 percent of the farmers who own a donkey beat any donkey that they have. The same point could be made with the determiner less than 100 percent of the, which should be synonymous with not every, under the usual interpretation.

$$
\begin{aligned}
& \text { a. Less than } 90 \text { percent of the farmers who own a donkey beat it. } \\
& \operatorname{LESS} 90 \%(\{x \mid \exists y[\operatorname{FARMER}(\mathrm{x}) \wedge \operatorname{DONKEY}(\mathrm{y}) \wedge \text { OWN }(\mathrm{x}, \mathrm{y})]\}, \\
& \{\mathrm{x} \mid \exists \mathrm{y}[\operatorname{FARMER}(\mathrm{x}) \wedge \operatorname{DONKEY}(\mathrm{y}) \wedge \operatorname{OWN}(\mathrm{x}, \mathrm{y}) \wedge \operatorname{BEAT}(\mathrm{x}, \mathrm{y})]\})
\end{aligned}
$$

b. LESS $90 \%(\mathrm{~A}, \mathrm{~B}) \Leftrightarrow \operatorname{card}(\mathrm{A} \cap \mathrm{B})<0.9 \cdot \operatorname{card}(\mathrm{A})$

I would like to propose that not every, contrary to received opinion, cannot be rendered by the logical constant NOTEVERY defined in (6.b). Rather, sentences of the form not every $A B$ are primarily used to deny an explict or implicit universal claim of the meaning $\operatorname{EVERY}(\|A\|,\|B\|)$. In this they are similar to sentences of the form It is not the case that $S$, or It is not true that $S$, which are typically used to deny an explicit or implicit claim $\|S\|$. This is obvious in the case of contrastive negation, when the contituent every is in focus, but also holds in other cases. In contrast, the truth-conditionally equivalent quantifier less than 100 percent of the cannot be used as easily in this way:

a. A: All the politicans are crooks. They just work for their own pocket.

b. B: Well, not every politician wants to enrich himself.

c. B: \# Well, less than 100 percent of the politicians want to enrich themselves.

A consequence of this analysis is that not every, in its idiomatic use, is not downward entailing in its nuclear scope. Recall that a quantified statement of the form $Q A B$ is downward entailing in $B$ iff it entails, for every $B^{\prime}$ with $\|B\| \subseteq\|B\|$, that $Q A B^{\prime}$. Now, if a statement of the form Not every $A B$ is possible only as a denial of a contextually present universal statement EVERY $(\|A\|,\|B\|)$, then statements like Not every $A B^{\prime}$, with $\|B\| \subset\|B\|$, are not, in general, felicitous in the context in which Not every $A B$ has been uttered. Hence the issue of whether Not every $A B$ is downward entailing or not does not arise. Independent evidence for that comes from the fact that negative polarity items, which in general indicate downward entailing contexts, do not occur in the nuclear scope of not every. This is in sharp contrast with quantifiers like less than 90 percent of:

a. *Not every tourist will ever visit Neuschwanstein.

b. Less than 90 percent of the tourists will ever visit Neuschwanstein.

Now, if the primary function of sentences of the type not every $A B$ is to deny universal claims EVERY $(\|A\|,\|B\|)$, then we should expect that, in case the universal claim happens to be a donkey sentence with a dependent variable, that the dependent variable is interpreted in the way characteristic for the sentence being denied, that is, characteristic for universal quantifiers. That is, we should 
expect that the dependent variable is interpreted existentially. Consequently, we can uphold Rooth's Generalization against Kanazawa's objection.

\section{Total and Partial Predicates in Plural Predications and Donkey Sentences}

Let me leave the subject of existential and universal interpretations of dependent variables for a moment. Consider the following example:

(10) a. I returned to the house because I thought I had left the windows open.

b. But when I came back I found that the windows were closed.

Clearly, the preferred interpretation of (10.a) is that I thought that I had left one or more of the windows open, whereas the preferred interpretation of $(10 . b)$ is that I found out that all the windows were closed.

Yoon (1994, to appear), who has investigated this phenomenon, proposes a lexical distinction between total and partial predicates. If we apply a total predicate like closed to an individual with parts, like the referent of the windows, we get a true sentence only if the predicate applies to every part. If we apply a partial predicate like open to it, then we get a true sentence already if the predicate applies to some of the parts. In a sense, to be closed indicates the absence of openness, whereas to be open indicates the mere presence of openness within an object. If $\mathrm{OPEN}(\mathrm{x})$ expresses that all parts of $\mathrm{x}$ are open, then we can render the English predicates open and closed as follows, where $\subseteq$ denotes the part relation.
a. open: $\lambda \mathrm{x} \exists \mathrm{y}[\mathrm{y} \subseteq \mathrm{x} \wedge \operatorname{OPEN}(\mathrm{y})]$
b. closed: $\lambda \mathrm{x} \neg \exists \mathrm{y}[\mathrm{y} \subseteq \mathrm{x} \wedge \operatorname{OPEN}(\mathrm{y})]$

Other examples of total/partial predicates are clean/dirty, healthy/sick, dry/wet, fail/pass, smooth/rugged, and empty/filled.

Without doubt, the total vs. partial interpretations of predicates like closed and open is an important phenomenon of semantic interpretation that has not yet received the attention it deserves. However, it seems that it is not strictly a lexical property, as Yoon (1994) has proposed. For imagine the following situation: The local bank has a safe that is accessible only through a hallway with three doors, all of which must be open to reach the safe.

(12) a. I could reach the safe because the doors were open.

b. I could not reach the safe because the doors were closed.

Under the given circumstances, (12.a) expresses the fact that all the doors were open, whereas (12.b) expresses the fact that at least some of the doors were closed. As the totality vs. partiality of the interpretation is shifting with the context, it cannot be just a lexical property. 
Here I will not try to develop a theory of total and partial interpretations of predicates. Regardless how their semantic behavior will ultimately be explained, Yoon (1994) observes that those predicates show similar differences in interpretation with donkey sentences:

(13) a. Usually, if a man has a garage with a window, he keeps it closed while he is away.

b. Usually, if a man has a garage with a window, he keeps it open while he is away.

(14) a. Most boys who had a baseball card in their pockets kept it clean while playing in the mud.

b. Most boys who had a baseball card in their pockets got it dirty while playing in the mud.

The preferred interpretation of (13.a) has the dependent variable interpreted universally; to count as a verifying case, a man that has a garage with a window must keep all the windows closed. The preferred interpretation of (13.b) is existential; it is sufficient that the man keeps at least one of the windows open. Examples (14) have the same preferred interpretations. We find that total predicates like closed and clean applied to the dependent variable lead to a universal interpretation, and that partial predicates like open and dirty lead to an existential interpretation.

This phenomenon is quite subtle, and so Yoon (1994) designed a controlled experiment. 50 subjects were exposed to written test sentences. There were two test sentences per category (total/partial predicates in plural predications, and corresponding total/partial predicates on the dependent variable of a donkey sentence). No subject was exposed to both members of a pair of test items, that is, no subject had to judge both a sentence like The windows are open and The windows are closed, in order to prevent subjects from attempting to stay consistent with their answers. Furthermore, the test material contained many distractor items. The subjects were instructed to read each sentence separatly and judge whether the sentence could be truthfully asserted in the described situation or not. Here is an example for each of the four categories:

a. The children are sick.

Situation: Susan has 5 children. 3 of them have come down with the flu while the other 2 are healthy. (Expected answer: True)

b. The children are healthy.

Situation: Susan has 5 children. 2 of them have come down with the flue while the other 3 are healthy. (Expected answer: False).

(16) a. Every farmer who owned a donkey kept it healthy during the rainy season.

Situation: We have 5 farmers. One of them owned one donkey and kept it healthy during the rainy season. The other 4 each owned 10 donkeys, and each let 3 or 4 of their donkeys get sick during the rainy season while keeping the others healthy. (Expected answer: False). 
b. Every farmer who owned a donkey let it get sick during the rainy season.

Situation: We have 5 farmers. 2 of them each owned one donkey and let it get sick during the rainy season. The other 3 owned 10 donkeys and each let 2 or 3 of their donkeys get sick during the rainy season while keeping the others healthy. (Expected answer: True)

With 100 answers per category (two sentences and 50 subjects), Yoon obtained the following result:

(17) a. Predication on sum individual with total predicate: $84 \%$ as predicted. Predication on sum individual with partial predicate: $82 \%$ as predicted.

b. Donkey sentences with total predicate: $74 \%$ as predicted. Donkey sentences with partial predicates: $78 \%$ as predicted.

These results are highly interesting. For one thing, (17.a) establishes that predicates like closed and open are indeed preferably interpreted as total and partial, respectively. Secondly, (17.b) shows that these predicates lead preferably to a universal or existential interpretation when predicated on the dependent variable of a donkey sentence. Finally, (17.a) and (b) together establish a correlation between total/partial predications on sum individuals and universal/existential predications on the dependent variable of donkey sentences.

Now, the dependent variable in examples (13) and (14) is a singular pronoun, a situation for which the notion of total and partial predicates is not applicable. So this correlation comes as a surprise for the classical representation of donkey sentences. Perhaps this points to a flaw in the classical representation?

\section{Consequences for the Representation of Donkey Sentences}

Yoon (1994) argues that the correlations in (13) and (14) indeed should lead to a revision of the received representation of donkey sentences. She proposes that the dependent variable should be interpreted as the sum individual that consists of all the individuals that its antecedent can be anchored to. The predicate on the dependent variable in the nuclear scope then is predicated on this sum indivdual. In case this predicate is a total or partial predicate, it will lead to a universal or existential interpretation, respectively. This predicts that (18.a) has a universal interpretation, and (19.b) has an existential interpretation.

(18) a. Every boy who had a baseball card kept it clean.

b. Analysis by way of paraphrase: Every boy who had a baseball card kept the baseball card(s) that he had clean.

c. The baseball cards that he had were clean. (total/universal) 
a. Every boy who had a baseball card got it dirty.

b. Analysis by way of paraphrase: Every boy who had a baseball card got the baseball card(s) that he had dirty.

b. The baseball cards that he had were dirty. (partial/existential)

One problem of this analysis is that the donkey pronoun (here, $i t$ ) is singular, but has to be spelled out by a potentially plural noun phrase. But Lappin (1989), who proposes a similar representation, argues that this is because the number of the pronoun is triggered by purely syntactic agreement. Independent evidence for that comes from the number of the pronoun in the following cases:

a. Every farmer who owns at least one donkey beats it.

b. Every farmer who owns at most three donkeys beats them.

Another potential problem of this analysis is that it seems to predict that the predicate of the donkey pronoun may be collective, which is clearly not the case:

*Every farmer who owns a donkey rounds it up at night.

However, notice that the pronoun it must, of course, accomodate cases in which a farmer just owns a single donkey, and in this case the collective predicate round up could not be applied.

There are a number of proposals for the representation of donkey sentences along the lines indicated here. They are originally motivated by the maximality effect in the interpretation of pronouns as in the following cases (cf. Evans 1980):

(22) Harry owns some donkeys. Tom vaccinated them.

$\approx$ Tom vaccinated all the donkeys that Harry owns.

Theories like Kamp (1981) and Heim (1982) do not give us this interpretation of these so-called E-type pronouns. ${ }^{3}$ Examples like (22), as well as the universal interpretation of dependent variables, have led to the suggestion of alternative theories (cf. Heim 1990 for discussion).

For example. Neale (1990) proposes that donkey pronouns are spelled out as numberless definite descriptions derived from the syntactic form of the antecedent, essentially similar to the paraphrases in (18) and (19). Problems of this approach are that it is unclear how this syntactic copying should work in general, and that we certainly need semantic inferences for anaphora as in Every farmer who owns a donkey beats the animal.

Lappin (1989) proposes semantic representations of the following type, where the donkey pronoun refers to the elements in the highlighted intersection. One problem here is that the anaphoric relation between the two highlighted sets in the following example is not formally captured: 


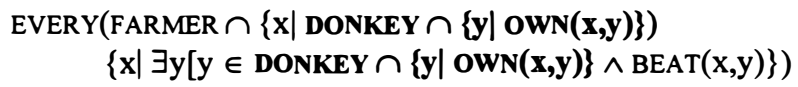

Chierchia $(1992,1995)$ proposes that donkey pronouns can be either bound (leading to an existential interpretation) or free (leading to an E-type reading). Free pronouns denote functions that are contextually supplied $\backslash$, as illustrated in (24). A problem with this approach is that there is no theory about how the function $f$ is to be construed. It should also be noted, as Chierchia wants to account for the existential vs. universal interpretation of the dependent variable, that he does not provide for an explanation of Rooth's Generalization.

$$
[\operatorname{EVERY}(\{\mathrm{x} \mid \exists \mathrm{y}[\operatorname{FARMER}(\mathrm{x}) \wedge \operatorname{DONKEY}(\mathrm{y}) \wedge \operatorname{OWN}(\mathrm{x}, \mathrm{y})]\},\{\mathrm{x} \mid \operatorname{BEAT}(\mathrm{f}(\mathrm{x}))\}] \text {, }
$$
where $f=\lambda x[$ THE DONKEY(S) THAT $x$ OWNS $]$

Lappin and Francez (1994) assume just the functional interpretation But they hold that many functions can be selected, two of them being illustrated in (25). The problems are similar to Chierchia's theory: No account is given for how the functions are construed, and Rooth's Generalization remains unexplained.
a. $\mathrm{f}=\lambda \mathrm{x}[$ THE DONKEY(S) THAT $\mathrm{x}$ OWNS $]$
b. $\mathrm{f}=\lambda \mathrm{x}$ [THE BIGGEST DONKEY $\mathrm{x}$ OWNS]
c. $\mathrm{f}=\ldots$

Yoon (1994) herself proposes an analysis within extended DRT (cf. Kamp \& Reyle 1993). Her DRS construction rules lead to discourse representations of donkey sentences in which quantification is only over the independent variable (x), cf. (26). The dependent variable (y) in the restrictor triggers the formation of an embedded box that contains all the descriptive predicates of which $y$ is an argument. We form the sum over $y$ under this description $(\Sigma y)$ and introduce a discourse referent $Z$ that is identified with that sum.

Every farmer who owned a donkey kept it healthy.

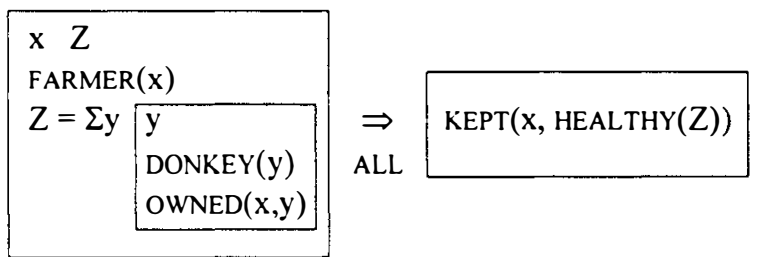

In the nuclear scope, the donkey pronoun can only be interpreted via the discourse referent $Z$. If the nuclear scope contains a total or partial predicate, it is interpreted with the preferences that we have established. So, HEALTHY(Z) will be interpreted as total, leading to a universal interpretation of the dependent variable. Also, notice that for each instantiation of the independent discourse referent there is a 
unique instantiation of the dependent discourse referent. This means that we do not have to record, with the quantification symbol $\Rightarrow$, which discourse referent the quantifier is supposed to quantify over.

\section{Sum Predications and Pragmatic Strenghtening}

Yoon's representation predicts the universal or existential interpretation of dependent variables in case predications with total and partial predicates are involved, but it does not capture Rooth's Generalization, which was formulated for predicates that do not fall into the total/partial category. I would like to propose that Rooth's Generalization follows from the way how predications on sum individuals are understood in general. Observe the following examples; I have given a straightforward semantic representation of the English sentences that stays close to surface structure, followed by an analysis how (a) is actually understood.

a. The windows are made of security glass.

b. MADE OF SECURITY GLASS(THE WINDOWS)

c. $\forall \mathrm{x}[\mathrm{x} \subseteq$ THE WINDOWS $\rightarrow$ MADE OF SECURITY GLASS( $\mathrm{x})]$

a. The windows are not made of security glass.

b. $\neg$ [MADE OF SECURITY GLASS(THE WINDOWS)]

c. $\neg \exists \mathrm{x}[\mathrm{x} \subseteq$ THE WINDOWS $\wedge$ MADE OF SECURITY GLASS( $\mathrm{x})]$

(27.a) is preferably interpreted as (27.c), 'All the windows are made of security glass', whereas (28.a) is preferably interpreted as (28.c), 'None of the windows are made of security glass'. Notice that (28.a) is not simply the logical negation of (27.a), in contrast to what is suggested by the surfacy representations (27.b) and (28.b). One possible explanation of this discrepancy is that (28.b) is not the right representation of (28.a) after all. Rather, the negation in (28.a) should be predicate negation, which leads to the following representation:

a. The windows are not made of security glass.

b. [ $\neg$ MADE OF SECURITY GLASS(THE WINDOWS)]

c. $\forall \mathrm{x}[\mathrm{x} \subseteq$ THE WINDOWS $\rightarrow[\neg$ MADE OF SECURITY GLASS $](\mathrm{x})]$ $\Leftrightarrow \forall \mathrm{x}[\mathrm{x} \subseteq$ THE WINDOWS $\rightarrow \neg[$ MADE OF SECURITY GLASS $(\mathrm{x})]]$ $\Leftrightarrow \neg \exists \mathrm{x}[\mathrm{x} \subseteq$ THE WINDOWS $\wedge$ MADE OF SECURITY GLASS $(\mathrm{x})]$

However, the assumption of predicate negation does not help in many other cases that are similar to (28) as they express some negation of (27) that is not simply logical negation. Consider the following cases:

(30) a. Mary believes that the windows are made of security glass.

b. Mary doubts that the windows are made of security glass.

(31) a. Many people believed that the windows were made of security glass.

b. Few people believed that the windows were made of security glass. 
(30.a) reports a belief of Mary that all the windows are made of security glass, and (b), that none of them is made of security glass. (31.a) says that many people believed that all the windows were made of security glass, whereas (b) says that few people believed that any of them was made of security glass. At least, these seem to be the preferred interpretations. In these examples, the constituent sentence the windows are made of security glass is preferably understood as involving a universal quantification over the windows in the (a) case, and as a (narrowscope) existential quantification in the (b) case. - We find similar tendencies for NPs denoting sum individuals in object position:

a. Mary has read the files on her desk.

b. Mary has not read the files on her desk.

(32.a) is preferably understood as saying that Mary has read every file on her desk, whereas (32.b) is preferably understood as saying that Mary has read none of the files on her desk. Notice that even if we analyze not here as predicate negation, pure logic would give us another interpretation, namely, that Mary has not read every file on her desk (i.e., she may have read some).

Yoon (1994) included negated and non-negated sentences in the test reported in section (4) above. Her result for sentences with stative predicates is as follows (again, 50 subjects, 2 sentences per category):

a. Non-negated sentences: $90 \%$ universal interpretation.

b. Negated sentences: $76 \%$ (narrow scope) existential interpretation.

This correlation has not gone completely unnoticed, as I found out recently. Lappin (1989) argues that plural pronouns and conjunctive NPs in the scope of upward-entailing operators receive a "conjunctive", i.e. universal, interpretation, and in the scope of downward-entailing operators, a "disjunctive", i.e. existential, interpretation. Lappin considers the following examples:

(34) a. No man found them.

b. No one saw John and Mary at the party yesterday.

c. Less than five people wanted Max and Sally to address the meeting.

In each case, the disjunctive or existential interpretation is preferred: (34.a) says that no man found any of them, (b) says that no one saw either John or Mary, and (c) says that less than five people wanted either Max or Sally to address the meeting. ${ }^{4}$ In all these cases we find the existential interpretation of the NP denoting a sum individual.

The data discussed in this section then lead to the following observation, which I would like to call Lappin's Generalization: 

A non-collective predication $\mathrm{P}(\mathrm{x})$ on a sum individual $\mathrm{x}$ is preferably interpreted as
(i) $\forall \mathrm{y}[\mathrm{y} \subseteq \mathrm{x} \rightarrow \mathrm{P}(\mathrm{y})]$, if $\mathrm{P}(\mathrm{x})$ is in an upward entailing environment,
(ii) $\exists y[y \subseteq x \wedge P(y)]$, if $P(x)$ is in a downward entailing environment.

The restriction to non-collective predications excludes the application of this principle to sentences like The students gathered or The students did not gather.

A statement like (35) is still a bit unsatisfactory, as it involves a very specific interpretation rule just for the case of plural predications. We should try to derive Lappin's Generalization from more general principles. Take again example (27) and (28) on their preferred (b) and dispreferred (c) interpretations:

(36) a. The windows are made of security glass.

b. $\forall \mathrm{x}[\mathrm{x} \subseteq$ THE WINDOWS $\rightarrow$ MADE OF SECURITY GLASS( $\mathrm{x})]$

c. $\exists \mathrm{x}[\mathrm{x} \subseteq$ THE WINDOWS $\wedge$ MADE OF SECURITY GLASS $(\mathrm{x})]$

(37) a. The windows are not made of security glass.

b. $\neg \exists \mathrm{x}[\mathrm{x} \subseteq$ THE WINDOWS $\wedge$ MADE OF SECURITY GLASS( $\mathrm{x})]$

c. $\neg \forall \mathrm{x}[\mathrm{x} \subseteq$ THE WINDOWS $\rightarrow$ MADE OF SECURITY GLASS $(\mathrm{x})]$

If we compare the preferred interpretations and the dispreferred interpretations in terms of their logical strength, we arrive at the following observation: For (36), the preferred interpretation, (36.b), logically entails the dispreferred interpretation, (36.c). Similarly for (37): The preferred interpretation (37.b) logically entails the dispreferrred interpretation (37.c). In general, the preferred interpretations are logically stronger than the dispreferred interpretations. This holds for the other cases we have considered as well.

What this suggests is that in predications on sum individuals, the logically stronger interpretation is preferred. More precisely, I would like to propose the following two hypotheses (38) and (39):

If a predicate $\mathrm{P}$ applies to a sum individual $\mathrm{x}$, grammar does not fix whether the predication is universal $(\forall y[y \subseteq x \rightarrow P(y)])$ or rather existential $(\exists y[y \subseteq x \wedge P(y)])$, except if there is explicit information that enforces one or the other interpretation.

Explict information that enforces a particular interpretation could be the presence of a universal quantifier, like all the windows, of a distributive operator, like in are each made of security glass, or interpretations of the predicate $\mathrm{P}$ that are lexically enforced or situationally preferred, e.g. if $\mathrm{P}$ is a total or partial predicate like are clean or are dirty.

If grammar allows for a stronger or a weaker interpretation of a structure, choose the one that results in the stronger interpretation of the sentence, if consistent with general background assumptions! 
Lappin's generalization (35) then follows from the interpretation rule for plural predicates (38) and the general pragmatic rule (39). The question now is whether these two rules can be independently motivated.

The interpretation rule (38) is, in some sense, a null hypothesis. Grammar has to specify the truth conditions for $\mathrm{P}(\mathrm{x})$ if $\mathrm{x}$ is an atomic individual. Furthermore, it is natural to assume that the truth of $\mathrm{P}(\mathrm{y})$, $\mathrm{y}$ being a sum individual, will somehow depend on whether $P$ applies to the parts of $y$. Now, if nothing indicates any particular proportion to which $P$ should apply to the parts of $y$, then the two natural extreme options are the universal interpretation and the existential interpretation.

For the pragmatic rule (39) there is some independent evidence. Dalrymple, Kanazawa, Mchombo \& Peters (1994) have proposed the "Strongest Meaning Hypothesis" for reciprocals (see also Kim \& Peters 1995 and Winter, this volume). This hypothesis states that reciprocal statements can be interpreted as involving a whole family of possible interpretations that are related to each other by logical strength, and that the interpretation actually selected is the one that yields the logically strongest truth conditions that are still compatible with the general background knowledge. Two illustrative examples are the following:

a. The five players know each other.

b. The five players sat alongside each other.

(40.a) selects the logically strongest interpretation of the reciprocal ('every player knows every other player'). This interpretation is physically impossible for (40.b), which settles for a weaker interpretation, but still for the strongest possible one, given the circumstances. Interestingly, the judgements change in the way predicted here when these sentences are embedded in downward entailing contexts:

a. The five players don't know each other.

b. Mary doubts that the five players know each other.

These examples preferably express (Mary's belief) that none of the five players knows any other player, which is not just the logical negation of (40.a). This shows that the absolutely weakest interpretation of the reciprocal is selected, which is the strongest one in this context.

The pragmatic rule (39) may be related to so-called "R-based Implicatures", cf. Horn (1984). These implicatures state that in certain circumstances, a speaker can derive the strongest possible interpretation that is consistent with what is said and with the the background knowledge. For example, from a sentence like Mary was able to solve the problem we can infer that Mary solved the problem.

Furthermore, (39) seems to be important for the interpretation of embedded questions. Lahiri (1991) has argued that in sentences like Mary mostly knows who passed the exam, the adverb mostly specifies the proportion to which Mary 
knows the answers to the embedded question. In case no explicit proportion is given, as in Mary knows who passed the exam, the proportion is assumed to be total or universal, that is, Mary knows all the answers. However, notice that a sentence like Mary does not know who passed the exam is typically interpreted as saying that Mary does not know any answer to this question, that is, we find an existential interpretation.

A possible objection against (39) is that it seems to predict that scopally ambiguous sentences like every data set was checked by a student always lead to the interpretation that entails the other interpretations (that is, the wide-scope interpretation of $a$ student). This is not so. Rule (39) forces the strongest interpretation that a particular linguistic structure can get. Under the assumption that scopally ambiguous sentences are disambiguated at some level in the syntaxsemantics interface, e.g. at a level of Logical Form, scopally ambiguous sentences lead to different structures as the input of interpretation.

One important issue at this point is: At which level is pragmatic strengthening to be evaluated within a structure that allows for multiple embeddings? Let us discuss the following example:

$$
\text { [s1 Mary doubts that [s2 the windows are not made of security glass]] }
$$

Evaluated at $S_{2}$, we would expect the existential interpretation. Evaluated at $S_{1}$, we would expect the universal interpretation. It appears to me that (37) actually can be understood in either way. This is reminiscent of the flip-flop effects in the licensing of polarity items. However, these effects are limited (cf. Krifka 1995), and we should expect similar limitations in the present case. For example, (37) can be understood as expressing a doubt of Mary with regard to a previously uttered sentence, $S_{2}$, which leads to pragmatic strengthening on the level of $S_{2}$.

\section{A Derivation of Rooth's Generalization}

Let us return to the universal and existential interpretations of the dependent variable of donkey sentences. It should be obvious by now how we can derive Rooth's Generalization from Yoon's representation of donkey sentences and Lappin's Generalization about the interpretation of plural predications. Let me illustrate this. According to Yoon, (43.a) is interpreted as in (b):

a. Every farmer who owns a donkey beats it.

b. Every farmer who owns a donkey beats the donkey(s) that he owns.

Grammar leaves it open whether the plural predication beats the donkey(s) that he owns is to be interpreted universally or existentially. The VP argument of every is upward entailing; so pragmatic strengthening leads to the universal interpretation. The following example is handled in the same way, except that the VP argument 
of no is downward entailing, which leads to a preference for the (narrow-scope) existential interpretation of the plural predication.

(44) a. No farmer who owns a donkey beats it.

b. No farmer who owns a donkey beats the donkey(s) that he owns.

These examples show that, in general, Rooth's Generalization can be derived. We have derived it from two independently justified ideas: First, Yoon's representation of donkey sentences that involve plural predications on the dependent variable, which was motivated by the interpretation of total and partial predicates. Second, Lappin's Generalization about how plural predications are interpreted in upward entailing and downward entailing contexts. This generalization in turn is a consequence of a plausible assumption about the underspecified interpretation of predications on sum individuals, and of an independently motivated rule of pragmatic strengthening.

Unfortunately, this is not all there is to say about the universal and existential interpretation of the dependent variable of donkey sentences. In the next section, I will mention an independent principle, and in the following section, I will review a couple of alternative explanations.

\section{An Additional Principle: Domain Narrowing}

It is well known that Rooth's Generalization can be violated in certain cases. Take the following example by Schubert \& Pelletier (1989), as statement about the behavior of men in a parking lot:

Usually, if a man has a quarter in his pocket, he puts it in the meter.

Clearly, the existential interpretation of the dependent variable is preferred. Barker (1993) has explained this by a phenomenon called domain narrowing. As quantified statements in general, donkey sentences allow for an implicit contextual narrowing of their restrictor. Making such restrictions explicit, a sentence like (45) can be paraphrased as follows:

Usually, if a man has a quarter in his pocket (and the parking meter is not broken, the parking meter is empty, etc.), he puts it in the meter.

Barker suggests that as soon as a man instantiates the required behavior by putting a quarter from his pocket in the meter, the highlighted implicit restriction changes to false, and said man is not required to put more quarters into the meter, even if he has more of them in his pocket.

I think that domain narrowing is very plausible, but it is a principle that is orthogonal to Rooth's Generalization. Domain narrowing will, by its nature, appear with episodic sentences, and not with statives, while Rooth's Generalization 
holds for stative predicates as well. It is still unclear, though, how domain narrowing of this sort should be integrated in the logical interpretation of quantifiers. .

\section{A Review of Other Suggestions}

Kadmon (1990) has proposed that donkey sentences like (1.a,b) with a singular dependent variable come with a uniqueness presupposition, here, that every farmer who owns a donkey owns exactly one donkey. In this case, the universal interpretation and the existential interpretation of the dependent variable collapse into one. But uniqueness can be cancelled, in contrast to bona fide presuppositions:

a. Every farmer who own a donkey beat it, and if a farmer owns two or more donkeys, he beats them too.

b. \# The current king of France visited the exhibition, although we all know that France is a republic.

Hence uniqueness cannot have the status of a presupposition. We can observe, however, a related effect: If there is a presupposition of non-uniqueness, then singular dependent variables are clearly disfavored. Knowing that all Iowa farmers that raise turkeys raise many of them, (48.a) is odd, and (48.b) is preferred. ${ }^{5}$

a. \# Most Iowa farmers that raise a turkey sell it for Thanksgiving.

b. Most Iowa farmers that raise turkeys sell them for Thanksgiving.

Barker (1993) suggested that donkey sentences like (1.a,b) rather come with a homogeneity presupposition, here that each farmer that owns a donkey either beats them all, or beats none of them. Again, the universal interpretation and the existential interpretation coincide in such models. But it turns out that homogeneity can be cancelled, hence cannot be a presupposition:

Most farmers in the village that own a donkey beat it. But Pedro, who owns two donkeys, beats only one of them.

Another attempt for an explanation was put forward by Kanazawa (1994). Sanchez-Valencia (1991) and Dowty (1994) have observed that the monotonicity properties of operators facilitate logical inferences. For example, if it is known that a context $\mathrm{X} \alpha \mathrm{Y}$ is downward entailing in $\alpha$, then it will follow that, if $\beta$ logically entails $\alpha$, then $\mathrm{X} \alpha \mathrm{Y}$ will logically entail X $\beta \mathrm{Y}$. Sanchez-Valencia and Dowty claim that natural language operators are typically upward entailing and downward entailing because such operators allow for easy computation of logical consequences.

Kanazawa (1994) proposes that dependent variables of donkey sentences are interpreted in a way as to preserve such inference patterns, and hence, to facili- 
tate the computation of logical entailments. He observes that we readily draw inferences like the following, due to the fact that every, no and some are monotone in their restrictor argument, and own and feed expresses a subconcept of own.

(50) a. Every farmer who owns a donkey beats it. $\Rightarrow$

Every farmer who owns and feeds a donkey beats it.

b. No farmer who owns a donkey beats it. $\Rightarrow$

No farmer who owns and feeds a donkey beats it.

c. Some farmer who owns and feeds a donkey beats it. $\Rightarrow$

Some farmer who owns a donkey beats it.

Now, these inferences only hold under the unversal interpretation of the dependent variable in (50.a), and under the existential interpretation in (50.b,c). Hence Kanazawa proposes a principle that in a donkey sentence with interpretation $Q(A$, $B)$, where $Q$ is a quantifier that allows for a upward or donward entailing interpretation on both arguments, the dependent variable is quantified in such a way (i.e., existentially or universally) that monotonicity inferences are preserved.

There are at least two problems to this analysis. One is that there are good arguments not to treat some, as in (50.c), as a quantifier of the same type as every and no. There are differences in the anaphoric potential in these quantifiers; for example, the premise of (50.c) can be continued with It likes that, in contrast to the premises of $(50 . \mathrm{a}, \mathrm{b})$. Quantifiers like some are to be treated as existential quantifiers, not as quantifiers that express a certain relation between two sets.

More seriously, Kanazawa's theory fails to make any prediction for quantifiers like most or less than 90 percent of the that are neither upward entailing nor downward entailing in their restrictor, although their tendency towards the universal or existential interpretation of the dependent variable in donkey sentences is as pronounced. For example, Most farmers who own a donkey beat it is most likely interpreted as universal on its dependent variable, and Less than 90 percent of the farmers who own a donkey beat it as existential. Rooth's Generalization, and hence the present paper, makes the right predictions in these cases.

\section{Endnotes}

A first version of this paper was presented in October 1994 at the conference "Recent Developments in Semantic Theory" in Blaubeuren, Germany, organized by the University of Tübingen, and a more developed one in September 1995 at the CSLI, Stanford University. I thank the participants at those occasions and at SALT VI for their stimulating discussion, in particular Gennaro Chierchia, Klaus von Heusinger, Eric Jackson, and Stanley Peters, and in particular my student Yangeun Yoon Kang. This paper was written during my residency at the Center for Advanced Study in the Behavioral Sciences, Stanford. I am grateful for financial support by the National Science Foundation, \#SES-9022192, and by the University Research Institute, University of Texas at Austin. 
${ }^{1}$ Rooth (1987) also considers as a possibility the case in which the dependent variable is quantified by the same quantifier that occurs in the overall quantification, in our example, MOST.

${ }^{2}$ See especially section (7) for exceptions.

${ }^{3}$ But see Krifka (1996) for a theory how maximal interpretations can be achieved within a framework of dynamic interpretation.

${ }^{4}$ Lappin (1989) is mostly about donkey sentences with plural antecedents of the dependent variable. He argues for an E-type analysis of donkey sentences (cf. (23)), but does not see the connection of this observation to existential vs. universal interpretations of Donkey pronouns.

${ }^{5}$ Thanks to Lee Baker, pers. communication, for these turkey sentences.

\section{References}

Barker, C. (1993). A Presuppositional Account of Proportional Ambiguity. Proceedings from Semantics and Linguistic Theory III, Cornell University, 118.

Chierchia, G. (1992). Anaphora and Dynamic Binding. Linguistics and Philosophy 15, 111-184.

Chierchia, G. (1995). Dynamics of Meaning. Anaphora, Presupposition, and the Theory of Grammar. University of Chicago Press.

Dalrymple, M., Kanazawa, M., Mchombo, S., and Peters, S. (1994). What do Reciprocals Mean? Proceedings from Semantics and Linguistic Theory IV, Cornell University.

Dowty, D. (1994). The Role of Negative Polarity and Concord Marking in Natural Language Reasoning. Proceedings from Semantics and Linguistic Theory $I V$, Cornell University.

Evans, G. (1980). Pronouns. Linguistic Inquiry 11, 337-362.

Heim, I. (1982). The Semantics of Definite and Indefinite Noun Phrases Ph.D. Dissertation, University of Massachusetts at Amherst. Published with Garland, New York.

Heim, I. (1990). E-Type Pronouns and Donkey Anaphora. Linguistics and Philosophy 13, 137-179.

Horn, L. (1984). Towards a New Taxanomy for Pragmatic Inferences: Q-based vs. R-based implicatures. George Town Round Table on Languages and Linguistics .

Kadmon, N. (1987). On Unique and Non-Unique Reference and Asymmetric Quantification. Ph.D. Dissertation, University of Massachusetts at Amherst.

Kadmon, N. (1990). Uniqueness. Linguistics \& Philosophy 13, 273-324.

Kamp, H. (1981). A Theory of Truth and Semantic Representation. In J. Groenendijk e.a., Formal Methods in the Study of Language, Mathematical Centre Tracts 135, Amsterdam, 277-322. 
Kamp, H. \& Reyle, U. (1993). From Discourse to Logic. Introduction to Model Theoretic Semantics of Natural Language, Formal Logic, and Discourse Representation Theory. Kluwer, Dordrecht.

Kanazawa, M. (1994). Weak and Strong readings of Donkey Sentences and Monotonicity Inferences in a Dynamic Setting. Linguistics \& Philosophy 17, 109-158.

Kim, Y., and S. Peters. (1995). Semantic and Pragmatic Context-Dependence: The Case of Reciprocals. Proceedings from Semantics and Lingustic Theory $V$, Cornell University.

Krifka, M. (1995). The Semantics and Pragmatics of Polarity Items. Linguistic Analysis 25, 209-257.

Krifka, M. (1996). Parametrized Sum Individuals for Plural Anaphora. To appear in Linguistics and Philosophy.

Lahiri, Utpal. (1991). Embedded Interrogatives and the Predicates that Embed Them. Doctoral dissertation, MIT, Cambridge.

Lappin, S. (1989). Donkey Pronouns Unbound. Theoretical Linguistics 15, 263289.

Lappin, S. \& N. Francez. (1994). E-type Pronouns, I-Sums, and Donkey Anaphora. Linguistics and Philosophy 17, 391-428.

Levinson, S. (1983). Pragmatics. Cambridge University Press.

Lewis, D. (1975). Adverbs of Quantification. In E. Keenan (ed.), Formal Semantics of Natural Language, Cambridge University Press, 3-15.

Link, G. (1987). Generalized Quantifiers and Plurals. In P. Gärdenfors (ed.), Generalized Quantifiers. Linguistic and Logical Approaches. Dordrecht, Reidel.

Neale, S. (1990). Descriptions. MIT Press, Cambridge, Mass.

Partee, B. H. (1984). Nominal and Temporal Anaphora. Linguistics and Philosophy 7, 243-286.

Rooth, M. (1987). Noun Phrase Interpretation in Montague Grammar, File Change Semantics, and Situation Semantics. In P. Gärdenfors (ed.), Generalized Quantifiers. Linguistic and Logical Approaches. Dordrecht, Reidel, 237-268.

Sanchez Valencia, V. (1991). Studies on Natural Logic and Categorial Grammar. Doctoral Dissertation, University of Amsterdam.

Schubert, L.K., Pelletier, J. (1989). Generically Speaking: Or, Using Discourse Representation Theory to Interpret Generics. In G. Chierchia, B.H. Partee, R. Turner (eds.). Properties, Types, and Meanings II: Semantic Issues, Dordrecht, Kluwer.

Winter, Yoad. (1996). What does the Strongest Meaning Hypothesis Mean? Talk presented at SALT VI.

Yoon, Y. (1994). Weak and Strong Interpretations of Quantifiers and Definite NPs in English and Korean. Ph.D. Dissertation, University of Texas at Austin.

Yoon, Y. (to appear). Total and Partial Predicates and the Weak and Strong Interpretation. Natural Language Semantics. 